\title{
SELECTION OF ALTERNATIVE LANDFILL LOCATION BY USING A GEOGRAPHICAL INFORMATION SYSTEM. EUROPEAN SIDE OF ISTANBUL. CASE STUDY
}

\begin{abstract}
One of the most difficult tasks encountered when implementing waste management practices in Turkey involves the selection of the most suitable area for a landfill. The Geographic Information System (GIS) which possesses the ability to imitate and process economic and environmental constraints, presents itself as a useful and effective decision support tool. This study will utilize the GIS to determine feasible alternative landfill areas on the European side of Istanbul, which has a high density population, showing that accurate selection results can be achieved at lower cost.
\end{abstract}

\section{INTRODUCTION}

A major problem encountered when employing the landfill method in solid waste disposal is the selection of the most suitable location for the landfill area. Increasing urbanization and solid waste generation rates, a shortage of appropriate land area in cities, the adverse reaction of the public to dumpsites [1] and legal constraints (some resulting from integration with European Union environmental legislation) all further tighten conditions nowadays for those siting landfills. With all these multi-criteria, choosing a right location for a landfill is becoming a more complex and time-consuming process. In this regard, decision making is very difficult without a decision support system that one can use to evaluate a number of conflicting factors. Siting a sanitary landfill

${ }^{1}$ Kirklareli University, Architecture Faculty, Department of Urban and Regional Planning, Kayali Campus, 39100, Kirklareli, Turkey, e-mail: goksel.demir@klu.edu.tr

${ }^{2}$ Istanbul Metropolitan Municipality, Geographical Information Systems Department, Istanbul, Turkey.

${ }^{3}$ Izmir Institute of Technology, Environmental Engineering Department, 35437, Izmir, Turkey.

${ }^{4}$ Bahcesehir University, Environmental Engineering Department, 34353, Besiktas, Istanbul.

${ }^{5}$ Istanbul Esenyurt University, Faculty of Engineering and Architecture, 34510, Esenyurt, Istanbul, Turkey. 
requires an extensive evaluation process in order to identify the best available disposal location. This location must comply with the requirements of governmental regulations and at the same time minimize economic, environmental, health and social costs [2]. The selection of an appropriate landfill area, which is also a sort of land use planning, comprises a good deal of spatial analysis: such as slope accounting, the assessment of conformity with re-classification and measurement of distance from different land use areas (buffer zone). Likewise, the evaluation of a new site requires considerable expertise in many social and scientific fields, including soil science, sociology, engineering, and economics [3].

In this sense, the Geographic Information System (GIS) which is capable of any type of spatial data processing and analysis, plays an important role as a decision support tool in the choice of alternative landfill locations. The use of the GIS technology provides criteria necessary for integration into the system, accelerates the selection period and gives more reliable results. With the development of the GIS, the landfill siting process is increasingly based on more sophisticated spatial analysis and modelling [4]. The selection of a solid waste disposal site is highly dependent on an appropriate consideration of the spatial variability of the hydraulic and hydrogeological characteristics of the basin. The advent of highly sophisticated computerised GIS systems, digitised map data, Landsat satellites and other remote sensing devices that help to define infrastructural and land use patterns has dramatically increased the potential of the GIS to aid in the development of a more systematic approach to landfill site selection. Such an approach should ideally combine the computerised GIS and geotechnical site investigation methods [5].

Currently, the GIS provides powerful capabilities for collecting, managing, retrieving, transforming and displaying spatial data about geographical objects and their non-spatial attributes. The next important step is choosing the most appropriate area from among the alternatives after the initial phase. A multi-criteria decision analysis can be used for this purpose by scoring alternative sites in terms of benchmarking (sorting), and provides the ability to determine the best alternative [6]. Some of the important applications of GIS for identifying potential waste disposal sites include the ones by Yesilnacar et al. [7], Koc-San [8], Aribo Looijen [9], Basagaoglu et al. [10], and Sener [11].

In Turkey, especially in recent years, the most widely used method for solid waste disposal is the sanitary landfill method. In $2010,54 \%$ of the $25276698 \mathrm{t}$ of waste produced was disposed of in landfills. $40 \%$ of this waste was sent to landfill sites in Istanbul only. Although the landfill method is widely known, primitive methods such as dumping, open burning, heaving into rivers and lakes, and combustion are used for solid waste disposal in $45 \%$ of Turkey [12]. Figure 1 shows the percentage of Turkish waste disposed of by the landfill method over a 15 year period. It describes an increasing trend.

Solid waste management (SWM) is at the forefront of environmental concerns in Turkey. The Ministry of the Environment and Forests requires municipalities to find municipal solid waste (MSW) landfill sites. On the other hand, there is lack of financial resources in some municipalities and strong public opposition to landfill site selection. 
Therefore, selection of appropriate landfill sites is very important for the municipalities in Turkey. One-fifth of Turkey's population lives in Istanbul and rapid population growth has been one of the most important problems of solid waste disposal. Until 1953 Istanbul's solid waste was discharged into the sea. Afterward, it was dumped in areas close to the city such as the Levent Industrial District, Seyrantepe, Uskudar and the Mustafa Kemal district. Over time, these dump sites were filled and subsequent incoming waste was dumped in new areas like Habipler, Ümraniye-Hekimbaşı, Yakacık, Aydınlı, Halkalı, Şişli, Feriköy and Kemerburgaz-Hasdal. In 1993, an explosion occurred as a result of this uncontrolled dumping, resulting in a loss of life and property damage $[13,14]$.

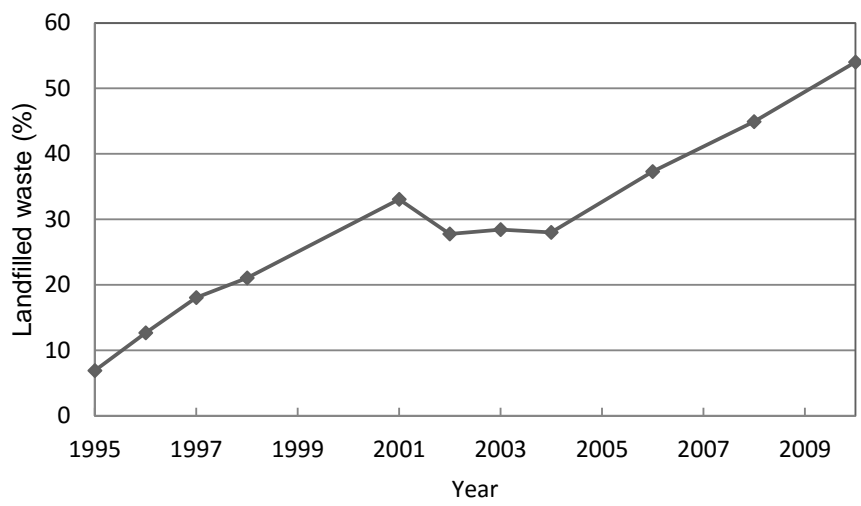

Fig. 1. The trend of use of the landfill method in waste disposal in Turkey

Nowadays, Istanbul has the best waste management practices in Turkey. The Istanbul Metropolitan Municipality (IMM) operates two sanitary landfills: Gokturk-Odayeri and Sile-Komurcuoda both with $9500 \mathrm{t}$ day capacity). In Istanbul, solid waste is collected by the district municipalities and gathered at one of the seven IMM transfer stations before being moved to the sanitary landfills [13]. The locations of these transfer stations and the current landfills of Istanbul are given in Fig. 2.

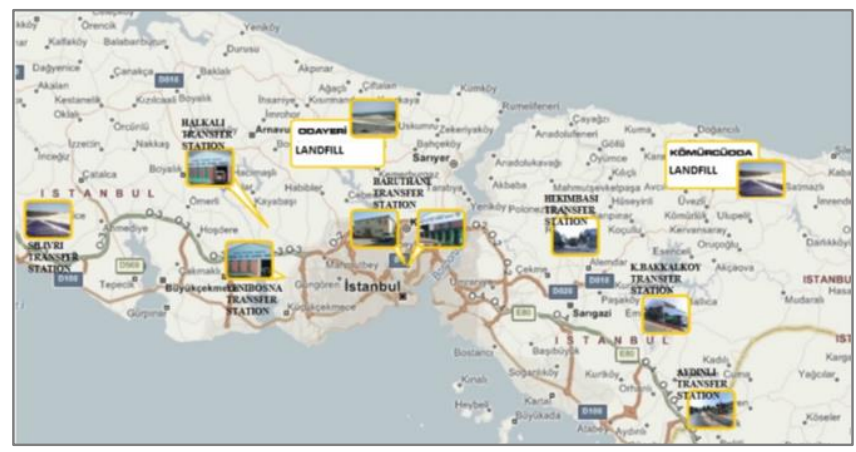

Fig. 2. Locations of transfer stations and current landfills of Istanbul [13] 
The opening of new landfills is required as a part of Turkey's integration into the EU. According to Turkey's 2007-2013 EU Strategy for Integrated Environmental Compliance Document [15], area selection for landfills is notable as one of the major problems related to solid waste management. In this case, the study area was identified as a certain part of the European side of Istanbul and a sample application was conducted in order to show how the use of GIS technology was the optimal means of selecting new landfill areas.

\section{EXPERIMENTAL}

Primarily related domestic and foreign literature, along with the studies of public, private and non-governmental organizations/institutions and relevant academic studies, have been examined for similar examples of GIS application within the boundaries of the IMM. Subsequently, this study was decided upon in order to fill a gap in landfill location selection in Istanbul.

As a first step, previous studies and regulations were taken into account in order to determine the criteria of selecting the location of landfills. Then, appropriate areas were designated according to each of the criterion and multiple maps were generated while factoring in the guidance of European Union and Turkish legislation. Information about relevant urban structures, transportation, lithology, altitude and satellite image data from 2008, all required by the GIS system, was provided from the IMM. The data was evaluated in terms of its reliability and its ability to meet the needs of the study and in the end superior and reliable datasets were compiled from the raw data. These numerical analysis datasets were created by using GIS:

- slope suitability map,

- settlement suitability map,

- suitability map based on lithology,

- suitability map based on roads.

According to the results of the conformity analysis for each of the maps generated, different areas were eligible for the appropriate landfill location. However, the goal of this study is to identify the locations that comply with the combination of all criteria. In order to achieve that desired result the intersect (overlay) analysis method, one of the ArcGIS tools, was used. Maps were generated according to the criteria targeted for this study and the restrictions of local regulations. Finally, the maps were intersected and those overlapping areas on the European side of Istanbul which met all criteria were indicated. In addition, the resulting overlapping areas were compared with the location of existing landfill sites.

The geology data supplied by the IMM does not cover the entirety of the European side of the Istanbul; therefore the boundaries of the geological map were considered a project limitation of this study, as shown in Fig. 3. 


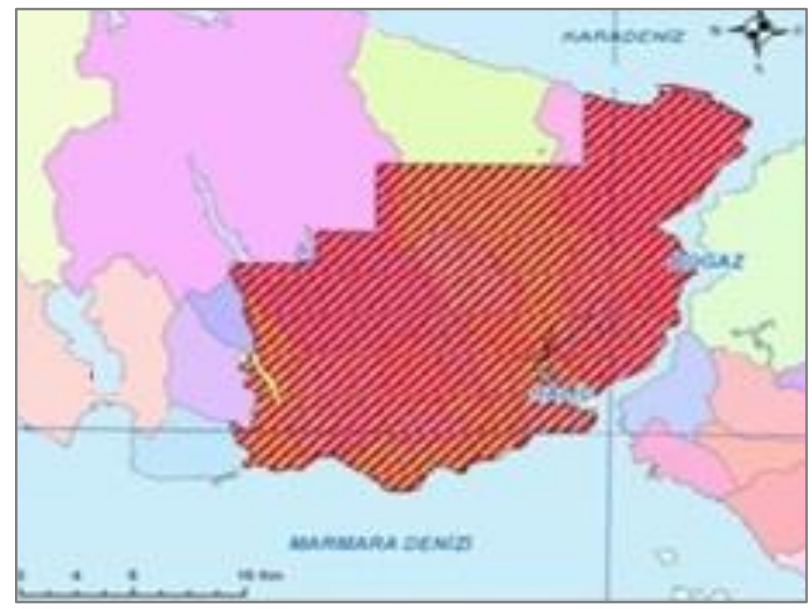

Fig. 3. The boundaries considered in this study for location maps of alternative landfill(s)

\section{USED CRITERIA}

The main element of the system applied in the landfill location selection process is the criteria to be considered. There are two types of criteria in the selection of the GIS-based landfill location for the identification of suitability of an area for a possible landfill: constraints and decision factors.

Constraints are the limitations which help to determine area location that is appropriate or inappropriate for a landfill. Additionally, those constraints are used to assess availability of an existing site as a landfill. For instance, according to Turkish regulation, landfills are not allowed $1000 \mathrm{~m}$ around of the residential areas, which is a constraint for landfills. Assessments made in this way produce results which are appropriate or inappropriate.

Decision factors are the criteria scored by increasing suitability of the alternative location(s) along a scale. In other words, factors define conformity between the lowest and highest conformity limit for the site analysis.

Even though the set of criteria for the selection of landfill location differs from project to project, a general list of criteria was prepared in order to determine the main elements that need to be addressed and to outline general criteria that are applicable to all projects. In this context, identified criteria and corresponding limit values in local regulations and literature are as follows: the distance to the nearest residential area should be at least 250-1000 m according to the type of storage area; sandy and loamy soils should not be selected in terms of soil texture; the maximum slope should be 15-20\%; the transportation distance should be a maximum of 10-30 km based on the size of settlement; and distance to the main transport network should be at least 
200-300 m. These four criteria are used in this study to identify alternative landfill locations on Istanbul's European side.

\subsection{RESIDENTIAL AREA CRITERION}

Turkish regulations for solid waste control state that distance to the residential area should be at least $1000 \mathrm{~m}$ for first class landfill sites storing hazardous waste. Regarding second class and third class landfill sites that store municipal waste and inert waste, the distance to residential area should be at least $250 \mathrm{~m}$. For the purposes of this study this criterion was set at $1000 \mathrm{~m}$. Buildings that are on the periphery of the study area are homogenized and then are buffered in ArcGIS software. Buffer analysis is used to search for the required geographic information within a pre-defined system boundary. The analysis is conducted for point, line or polygon characteristics of vector data. Buffer analysis may be conducted for a point, which is in the centre of a circle with a known radius. It may also be conducted for a line and at one or each side of that line with predefined distances. Buffer analysis may also be applied within or outside the borders of a polygon determined by distance.

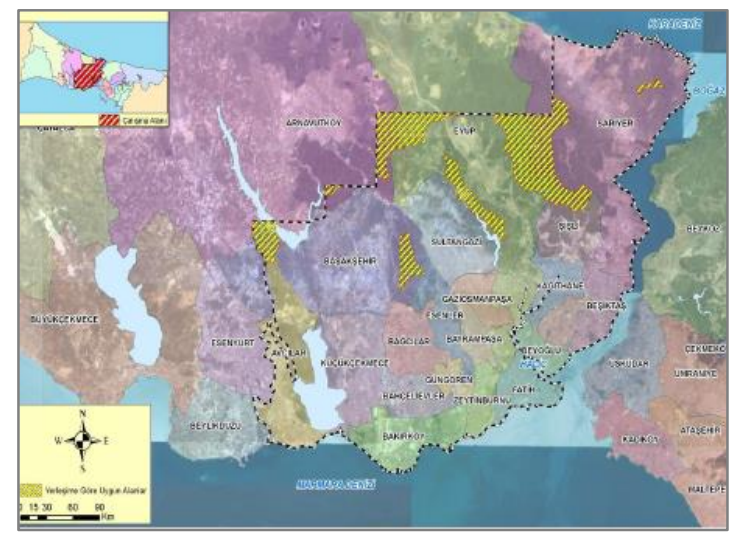

Fig. 4. Sites that meet the residential area criterion

As a result of buffering, which is conducted according to the residential area distance criterion, sites that remain outside of residential areas and therefore are alternative sites for landfilling are given in Fig. 4.

\subsection{ROAD CRITERION}

There should be a buffer zone of at least $100 \mathrm{~m}$ between landfill sites and roads [16]. On the other hand, landfill sites should not be located too far from road as the additional length of newly constructed connection roads will increase costs significantly. In this 
study, road data from IMM's corresponding database are used. Roads that are classified as main roads and highways are picked and $100 \mathrm{~m}$ of buffer zone are defined on both sides of these roads. Suitable sites identified through the road analysis are presented in Fig. 5. The area of suitable sites retrieved by road criterion is larger than the area retrieved by settlement criterion (Fig. 3) since the quantitative value used for the road criterion is smaller.

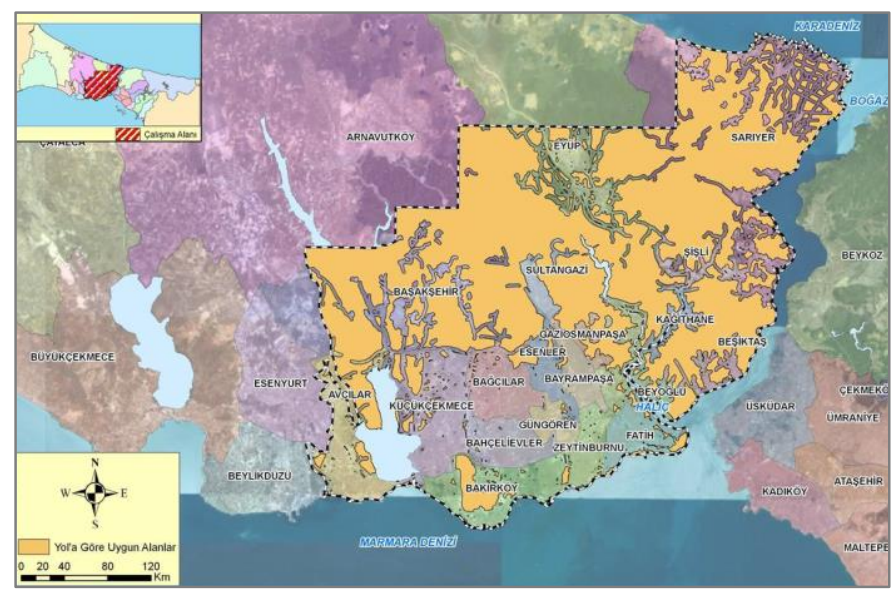

Fig. 5. Sites that meet the road criterion

\subsection{SLOPE CRITERION}

A landfill site should not have a slope that is steeper than $15 \%$ [7]. Sites with the slope values equal to or lower than $5 \%$ are the most appropriate ones for landfilling.

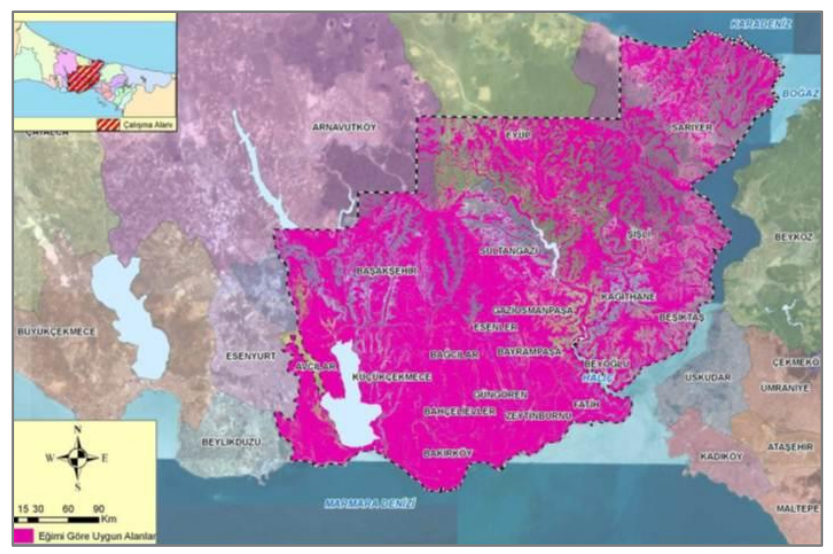

Fig. 6. Sites that meet the $15 \%$ slope criterion 
Since Istanbul is built on many hills, $15 \%$ is considered to be the appropriate slope value. Then, a numerical altitude model is used for the working field and the slope map is retrieved using geology data and the Slope tool, which is one of the tools of a Spatial Analyst. The slope map is classified according to the limit value and is given in Fig. 6 .

\subsection{LITHOLOGY CRITERION}

The construction of new landfills in karstic areas is prohibited under Turkish regulations for solid waste control. The properties of the most adequate areas are given in Fig. 7. Lithology is the impermeable structure of the rock and it is an important criterion for the prevention of leachate. The most suitable ground is clay for such areas and particularly those formations containing clay are preferred [17].

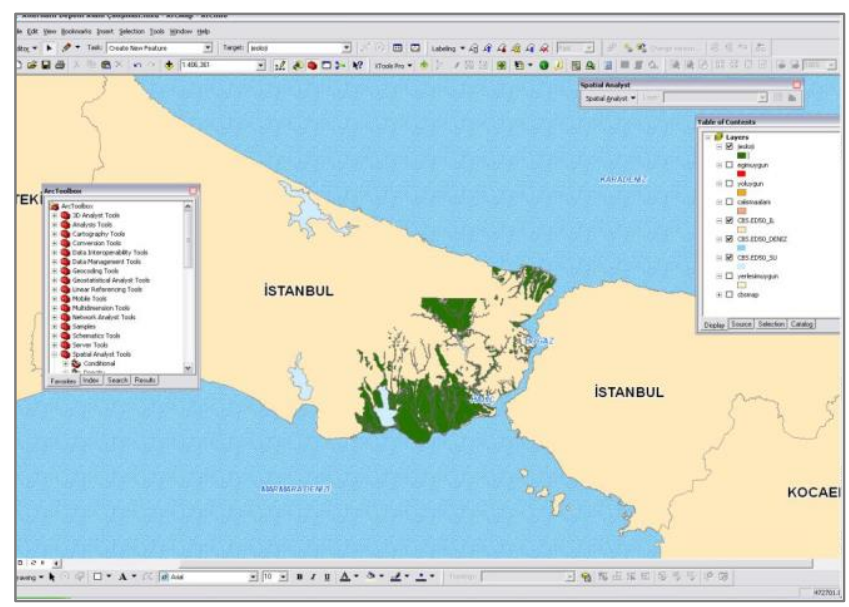

Fig. 7. Preparation of the map according to the lithology criterion

Clay layer that has a compacted depth of at least $60 \mathrm{~cm}$ or natural or synthetic material that gives the same impermeability is laid at the base of the landfill. Permeability coefficients for these materials should not exceed $10^{-8} \mathrm{~m} / \mathrm{s}$. For rocky soil with few cracks the permeability coefficient is considered to be $10^{-7} \mathrm{~m} / \mathrm{s}$.

Structured query language (SQL) was used, so the query was written in ArcGIS in order to show appropriate formations according to the used geology data (Fig. 8). In this study, required data and results were selected from millions of records within a short time using of SQL.

In the analysis with SQL, the most appropriate areas were identified and given in Fig. 8 , by ensuring the separation of other geological formations in terms of lithology. 


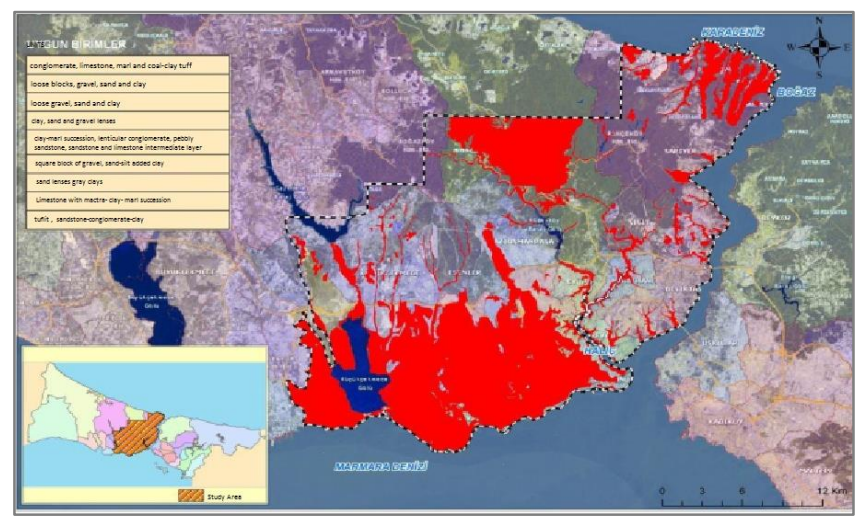

Fig. 8. Appropriate fields according to lithology criterion

\subsection{DETERMINATION OF THE APPROPRIATE FIELDS ACCORDING TO CRITERIA OUTCOMES}

Overlay analysis is the process of combining the data of two different layers both graphically and qualitatively. Intersect analysis, one of the overlay types, is made by overlapping more than one datum, and results obtained by intersection of the sets which show appropriate fields according to all criteria. Combine, intersect and identify commands are used in the application of overlay analysis. In this study, the intersect tool provided by ArcGIS was used to determine similar fields complied with slope, road and lithology criteria. A map of each criterion was superimposed; eventually cross-cutting areas that may be alternative landfills were identified and given in Fig. 9.

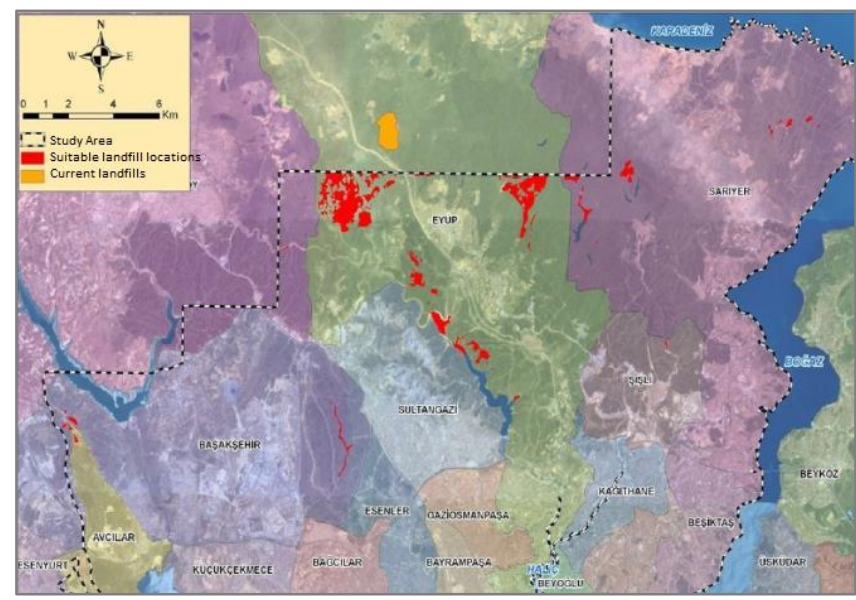

Fig. 9. Determined landfill areas by intersect analysis, which are matching each criterion 
Red parts of the map show the areas that can be used as landfills, and determined in accordance with the criteria used in this study. The portion marked in yellow is the current Gokturk-Odayeri landfill area. The Gokturk-Odayeri landfill remains outside the boundaries of the work performed in this study. It can however, be noted that the Gokturk Landfill Area is not compatible with the settlement criterion of this study once increasing population density is considered.

Suitable alternative landfill sites are generally located in the northern province of Istanbul, on the European side, especially in the Eyup district, which is close to current landfills.

\section{CONCLUSIONS}

There is a need for a huge amount of spatial data to be used in determining the most available sites for landfills, due to the existence of numerous factors affecting the decision-making process. Time-consuming, expensive and very labour-intensive traditional methods are inadequate in this regard and also give subjective results. Therefore, the GIS application, which is suitable for a large amount of data that cannot be analysed by conventional techniques, has become an important instrument, since GIS combines landfill site selection multi-criteria with analytical tools on a helpful platform. Due to the above-mentioned features, in recent years GIS has come to be preferred as an important strategic decision-making device in the process of landfill site selection.

In this study, a sample site was selected by using defined criteria which were determined according to relevant regulations and previous studies, and can be used by local authorities especially for the preparation of 1/5000 scale master plans. So far these focus on data relating to property-type and distance, other criteria were not considered in the landfill site selection process, therefore such a methodology is important in terms of healthy urbanisation located in a reasonable distance from landfills.

In this method, the quality of the data and applied methods of analysis, as well as the qualifications of the expert who determines weights of each criterion has significant effects on the results. The risk of uncertain results, high costs and long evaluation periods can be reduced with the GIS method. However, data checks must be repeated and selected lands should be authenticated in the final stage of site selection studies utilizing GIS. The method used in this study can provide more objective and realistic results regarding spatial dimension when compared to methods other than GIS.

In conclusion, the locations of existing landfills should be evaluated again in terms of settlement criteria in order to reduce negative habitant response and possible health problems. For new landfills and extension (adding new cells to existing landfills) constructions, such a methodology should be used by decision-makers. Such decision-making is an important step in the management of existing resources in a region. Owing to 
the wide variety effects associated with waste in landfills, the right decisions are required for sustainable development and a healthy environment.

\section{REFERENCES}

[1] NAS B., CAY T., IsCAN F., BERKTAY A., Selection of MSW landfill site for Konya, Turkey using GIS and multi-criteria evaluation, Environ. Monit. Assess., 2010, 160, 491.

[2] SUMATHI V.R., NATESAN U., SARKAR C., GIS-based approach for optimized siting of municipal solid waste landfill, Waste Manage., 2008, 28, 2146.

[3] Muttiah R.S., Engel B.A., Jones D.D., Waste disposal site selection using GIS-based simulated annealing, Comput. Geosci., 1996, 22 ( 9), 1013.

[4] Changa N., Parvathinathanb G., Breeden J., Combining GIS with fuzzy multicriteria decisionmaking for landfill siting in a fast-growing urban region, J. Environ. Manage., 2008, 87, 139.

[5] Allen A.R., Dillon A.M., O’BRIEN M., Approaches to landfill site selection in Ireland, [in:] P.G. Marinos, G.C. Koukis, G.C. Tsiambaos, G.C. Stournaras (Eds.), Engineering Geology and the Environment, Balkema, Rotterdam 1997, 1569.

[6] Burrough P.A., Principles of Geographical Information Systems for Land Resource Assessment, Clarendon Press, Oxford 1986.

[7] Yesilnacar M.I., Suzen M.L., Kaya B.S., Doyuran V., Municipal solid waste landfill site selection for the city of Şanliurfa-Turkey. An example using MCDA integrated with GIS, Int. J. Digital Earth, 2012, 5 (2), 147.

[8] Koc-San D., SAn B.T., Bakis V., Helvaci M., Eker Z., Multi-criteria decision analysis integrated with GIS and remote sensing for astronomical observatory site selection in Antalya province, Turkey, Adv. Space Res., 2013, 52, 39.

[9] ARIBo L., LoOIJEN J., GIS modelling for solid waste disposal site selection, Int. Conf. Advances in Engineering and Technology, Uganda, 2006.

[10] Basagaoglu H., Celenk E, Marino M.A., Usul N., Selection of waste disposal sites using GIS, J. Am. Water Res. Assoc., 1997, 33 (2), 455.

[11] SENER B., Landfill site selection by using geographic information systems, Environ. Geol., 2006, 49 (3), 376.

[12] Turkish Statistical Institute, Statistical Database, Available from: www.tuik.gov.tr

[13] Istanbul Metropolitan Municipality, Waste Management Department, Available from: http://www. ibb.gov.tr/tr-TR/kurumsal/Birimler/AtikYonetimiMd/Pages/AnaSayfa.aspx (in Turkish).

[14] Kolay U.E., Alternative Solid Waste Lands Landfill Site Selection Geographic Information System Based Sample Application, Master Dissertation at Bahcesehir University, Urban Systems and Transport Management Programme, 2012 (in Turkish).

[15] Ministry of Environment and Urbanisation, UÇES (AB Entegre Çevre Uyum Stratejisi), Available from: http://www.did-cevreorman.gov.tr/haber_detay.asp?id=13 (in Turkish).

[16] Turkish Landfill Directive, Official Journal Date: 26.03.2010. Official Journal Number: 27533, 2012 (in Turkish).

[17] Istanbul Environmental Protection Company, Personal Communication, 2014. 